\title{
Time to amend Section 135
}

\author{
Peter Cutajar and Michele Hampson
}

Section 135 of the Mental Health Act (1983) allows a Justice of the Peace, on information provided on oath by an approved social worker. to issue a warrant allowing any constable named in the warrant to enter, if need be by force, any premises in which there is reasonable cause to suspect that a person believed to be suffering from a mental disorder:

(a) has been, or is being, ill-treated, neglected or kept otherwise than under proper control; or

(b) being unable to care for himself, is living alone in any such place, and, if thought fit, to remove him to a place of safety.

The use of this section has increased steadily over recent years, being used 58 times in England in 1987/88 and 126 times in 1992/93 (Department of Health, 1995).

The clause "living alone" can cause difficulties in the use of this section. There seems to be no provision for the situation where all the members of the household may be suffering from a mental disorder. In such cases it may be impossible to know who is being ill-treated and by whom without a mental health assessment of each member. Each might be unable to care for themselves or might be receiving insufficient care from the others. The situation is further complicated when one or more of the members is under 18 years and where the Children Act 1989 must also be taken into consideration. The following case report highlights this difficulty.

\section{Case history}

The family consisted of a 44-year-old mother, a 16-year-old daughter, and a 12-year-old son, living together on a housing estate for four years. Both children attended a normal school, and the mother had difficulties with reading and writing. The family had few contacts outside of school, but a solicitor and a neighbour were used for support.

There was little contact with others following the end of the summer school term. Neither child returned to school at the beginning of the autumn term, but five weeks later the son did so and then was not allowed to re-enter the house by his mother and sister. A neighbour summoned the help of the social services. The son described how both his mother and his sister were preoccupied with black magic and believed that spirits could take over various members of the family in turn. He also believed that he could alter his appearance and that sometimes he would be an imposter. He said that both his mother and his sister would beat him in order to get his 'real' self back. By his account both his mother and his sister had similar beliefs which raised the possibility that the daughter was being similarly ill-treated. Childcare services were immediately alerted and the son was taken into temporary accommodation at a children's home and thence to a foster family. His psychotic symptoms diminished over 24 hours and he received close support and follow-up by the child and adolescent psychiatric team involved.

Over the next two days the mother and daughter stayed indoors refusing access to members of the local mental health team. It was therefore decided to gain access by applying Section 135 of the Mental Health Act for both the mother and daughter, as it was possible that both were suffering from mental illness and might require further assessment in hospital, under Part II of the Mental Health Act.

The Act requires a registered medical practitioner and an approved social worker to be present when the warrant is executed. The Act allows for the person to be taken to a place of safety. As the only information available came from a child who had himself exhibited psychotic symptoms, albeit briefly, it was felt appropriate for the doctor to be one approved under Section 12 of the Mental Health Act to assess the persons at home, with the social worker, to determine whether further assessment was necessary in hospital. A childcare social worker was also present to help assess whether attendance at hospital would be more appropriate in the care of the daughter. As both had psychotic symptoms, arrangements were made to admit them into separate wards of the same hospital. After admission, the mother's apparent delusional beliefs disappeared within hours and she remained as an informal patient. She was felt to be suffering from anxiety and depression and was treated accordingly. The daughter was detained on Section 2 of the Mental Health Act. It seemed likely that the daughter was the inducer of this folie $\dot{a}$ famille and that she 
might be suffering from a delusional disorder (persecutory type). Similar cases of folie à famille have been described in the literature (Glassman et al. 1987). The daughter's psychotic symptoms rapidly disappeared but she remained suspicious and was finally treated with trifluoperazine with good effect. Mother and daughter have returned home and at their request the son remains with foster parents.

At face value it appears that Section 135 could not have been used in this case, where two persons were still living together. However, the magistrates accepted the view that since the daughter was under 18 years of age, for the purpose of the Mental Health Act there was one adult living alone, with a minor, so that part (b) of the Section could be applied to the mother. The daughter was also suffering from a mental illness and could not be adequately cared for by her mother. Thus part (a) of the Section was implemented. The question then is what would have happened if the daughter had been over 18 years? Could one have argued that part (a) of the Section could apply to the more vulnerable of the two, and once that person is removed, the other person would now be living alone and may be subject to part (b) of Section 135? Clearly this is not entirely satisfactory. The Royal College of Physicians (1978) have made a recommendation that Section 135 should also provide for the situation where two mentally disordered people are living together and are unable to care for themselves, but as yet this has not been adopted (Cmnd. 7320, para. 2.21). We would agree and recommend that the clause "living alone" be dropped from the conditions for implementing Section 135, so that the Section could be applied to a household where it is felt that there is no member able to take adequate care of those who are mentally ill.

\section{Acknowledgement}

We are grateful to Linda Metcalfe, Senior Social Worker, Roseberry House, Nottingham, for her help and advice during the preparation of this paper.

\section{References}

DEPARTMENT OF HEALTH (1995) In-patients Formally Detained in Hospital under the Mental Health Act 1983 and Other Legislation, England: 1987-88 to 1992-93. Department of Health Statistical Bulletin 1995. London: Department of Health.

Glassman, J. M. S., Magulac, M. \& Darko, D. F. (1987) Folle a famille: shared paranoid disorder in a Vietnam veteran and his family. American Joumal of Psychiatry, 144, 658-660.

Royal College of PHYSICIANS (1978) Review of the Mental Health Act 1959. p. 17, Command 7320. Paragraph 2.21. London: HMSO.

* Peter Cutajar, Senior Registrar in Learning Disabilities, South Block, E Floor, Queen's Medical Centre, Nottingham NG7 2UH and Michele Hampson, Consultant Psychiatrist, Highbury Hospital, Bulwell, Nottingham

*Correspondence 